\title{
Congenital giant nevocellular nevus of the back with deep extension to the fat and fascia
}

\author{
Marcos RO Jaeger MD, Ronald M Zuker MD FRCSC FACS FAAP
}

MRO Jaeger, RM Zuker. Congenital giant nevocellular nevus of the back with deep extension to the fat and fascia. Can J Plast Surg 2006;14(1):45-48.

\begin{abstract}
The presence of deep pigmentation in a giant congenital nevus makes its complete removal very difficult and should be taken into consideration when planning for treatment. A clinical case in which the pigmented lesion was found to extend deep into the muscle fascia is described. The lesion was surgically removed with an acceptable functional and aesthetic result through the utilization of tissue expansion. The development of new surgical techniques and the expansion of laser technology will possibly provide new treatment options in the future. Emphasis should be placed on aesthetics and function, because the excision based only on oncological anticipation is no longer valid. The presence of deep pigmentation makes certain treatment options less effective than surgical ablation.
\end{abstract}

Key Words: Giant congenital nevi; Laser; Tissue expanders

\author{
Naevus cellulaire congénital géant dans le dos, \\ avec pénétration profonde dans le tissu \\ adipeux et le fascia
}

La présence d'une pigmentation profonde dans un naevus congénital géant rend son excision complète très difficile, et cet aspect devrait être pris en considération lorsque vient le moment de planifier le traitement. Voici un cas clinique de lésion pigmentée avec pénétration profonde dans le fascia. La lésion a été excisée convenablement des points de vue fonctionnel et esthétique par le recours à des expanseurs tissulaires. La mise au point de nouvelles techniques chirurgicales et le développement de la technologie laser déboucheront peut-être sur l'élaboration d'autres traitements. Une attention particulière devrait être portée aux aspects esthétique et fonctionnel, parce qu'aujourd'hui l'excision fondée sur le seul critère de la prévision oncologique ne suffit plus. La présence d'une pigmentation profonde rend certains traitements moins efficaces que l'excision chirurgicale.
Congenital pigmented nevi are found in approximately $1 \%$ Uof newborn infants, but $90 \%$ of them are very small. A giant congenital nevus (GCN), giant hairy nevus or nevocellular nevus represents a special group of melanocytic lesions that generally covers large areas of the body and have a potential risk for developing malignant melanoma (1). Factors often associated with the risk of malignant degeneration include location of the lesion, presence of neurocutaneous melanocytosis, and depth and distribution of the pigmentation. However, the risk of malignancy seems to be lower than previously reported, now expressed as a life-risk range of $2.3 \%$, with most cases tending to occur before adolescence (1-7).

In the plastic surgery clinic at The Hospital for Sick Children, Toronto, Ontario, children with a GCN are routinely seen by a dermatologist before the appointment with the plastic surgeon, and a complete workup to rule out neurocutaneous melanocytosis is done in selected cases. As a result of the referral, children often undergo a number of surgeries that have been thought to reduce the chances of malignant transformation. Nevertheless, the possibility of removing the entire lesion is impractical, especially in those children with a central nervous system component. Nevus cells could also, on occasion, be found after surgery at the skin closure sites or gradually migrating into the surface skin grafts $(8,9)$. If the risk is much lower than reported previously, and the real chances of completely eradicating the risk is impossible, we believe it is therefore appropriate to say that GCN removal is first a reconstructive and aesthetic surgical procedure rather than prophylactic cancer surgery (10-12). This should highlight that it is no longer necessary or often appropriate to remove such lesions and leave significant functional impairment and cosmetic disfigurement $(1,2)$.

Treatment options for removal of the GCN vary from serial excisions, skin grafting and expanded flaps to the utilization of laser. Despite of the high risk of complications, reconstruction with tissue expansion has been shown to be a very effective treatment option in the pediatric population (11). When surgery is indicated, one often starts with a minor operation consisting of a central elliptical resection within the nevus boundaries that serves to reduce the lesion and to give a better estimate of the depth of the lesion. Very often, serial excision followed by tissue expansion is used to provide new tissue to create another flap, so that all available skin becomes usable for reconstruction (11).

The present paper emphasises the importance of recognizing the worrisome deep extension of pigmentation occasionally seen in the GCN and raises considerations toward other treatment options. A clinical case in which the lesion was found to extend deep into the muscle fascia is described. The lesion was surgically excised and resurfaced by expanded skin flap reconstruction, with an acceptable functional and aesthetic result.

\section{CASE PRESENTATION}

A six-year-old boy was referred to the plastic surgery clinic after being seen by the dermatologist. On examination, he had multiple hyperpigmented plaques over his scalp, face, trunk and extremities. There was a giant melanocytic lesion on his back from approximately the T12 level to the lumbosacral area, with a further extension of the deeply pigmented lesion over the left buttock (Figure 1). In one of the scalp nevi,

Department of Plastic Surgery, The Hospital for Sick Children, Toronto, Ontario

Correspondence: Dr Ronald M Zuker, Suite 1524, 555 University Avenue, Toronto, Ontario M5G 1X8. Telephone 416-813-6447,

fax 416-813-6147,e-mail ronald.zuker@sickkids.ca 


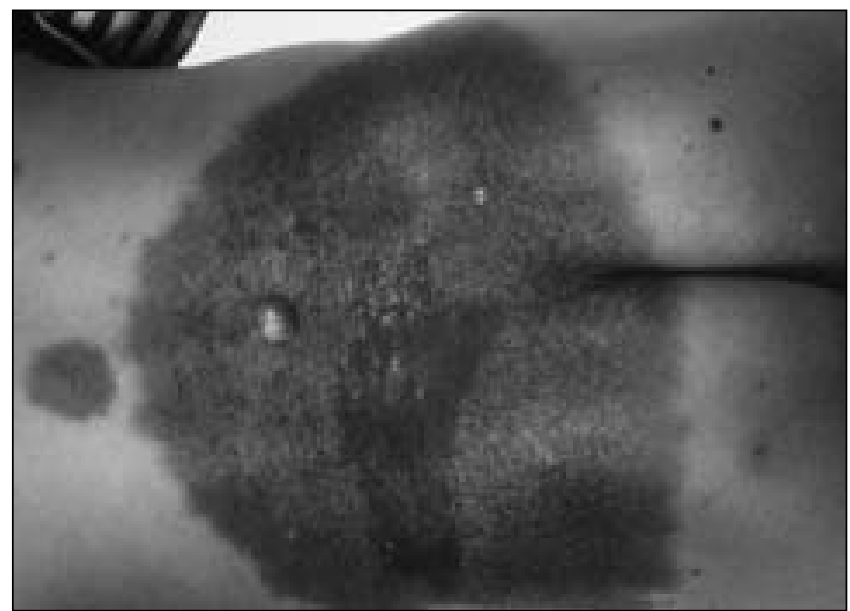

Figure 1) Giant melanocytic lesion on the back with further extension over the left buttock

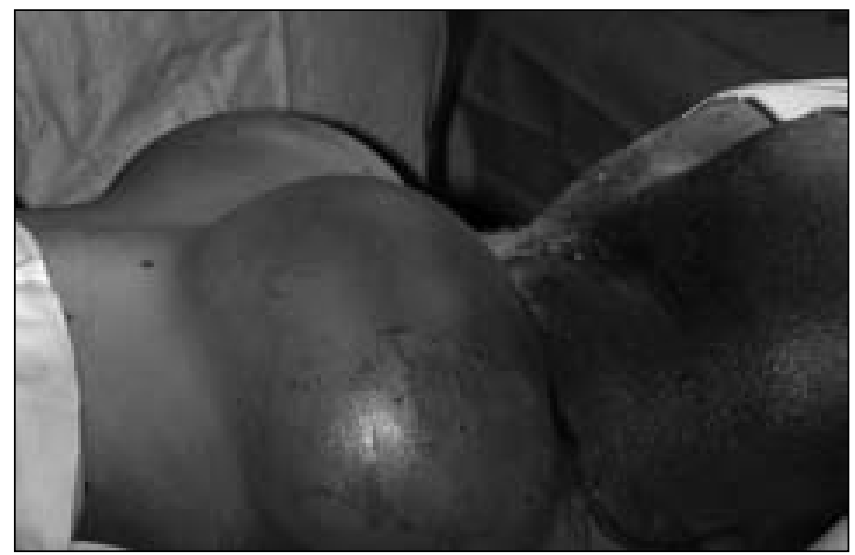

Figure 2) Preoperative appearance of the nevus on the back with area expanded above the lesion

hypertrichosis was noted. Nevi over the body ranged from the giant lesion noted on the back to small ones of a few millimetres in size over his extremities, as well as lesions measuring $2 \mathrm{~cm}$ in diameter in the scalp. The preoperative workup included magnetic resonance imaging of the cervical-thoracic-lumbar spine, which ruled out central nervous system involvement.

Surgical treatment consisted of central elliptical resection within the nevus and, six months later, the insertion of two tissue expanders beneath adjacent normal skin. Two expanders of $680 \mathrm{~mL}$ each were used.

Three months later, the expanders and the injection ports were removed (Figure 2). The specimen was resected and sent to pathology for identification (Figure 3). Attention was directed at the deep involvement (Figure 4). The expanded flaps were used for coverage of the defect. The pathology report confirmed the diagnosis of compound congenital nevus, with extensive subcutis involvement. The postoperative result was satisfactory, with the residual nevus being below the belt line (Figure 5).

\section{DISCUSSION}

The management of the GCN continues to evolve. Factors often associated with the possibility of malignant degeneration include location of the lesion, presence of neurocutaneous

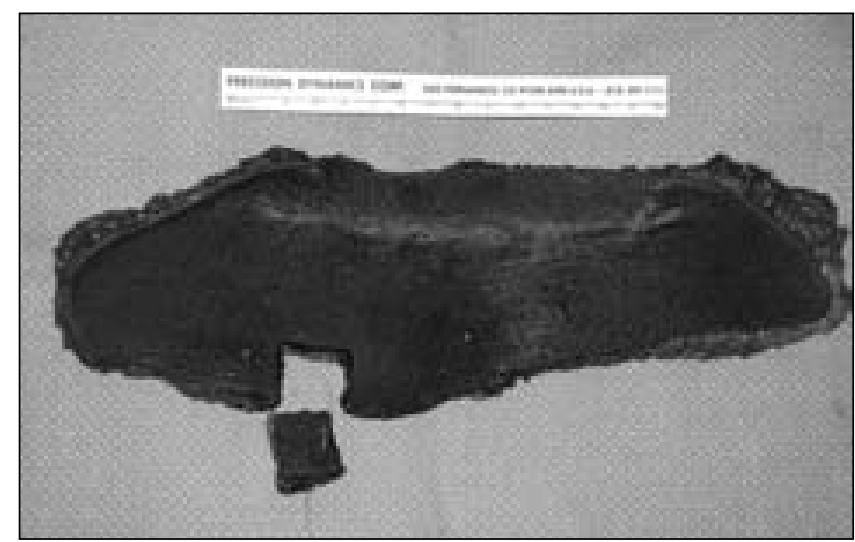

Figure 3) Intraoperative view of the specimen sent to pathology

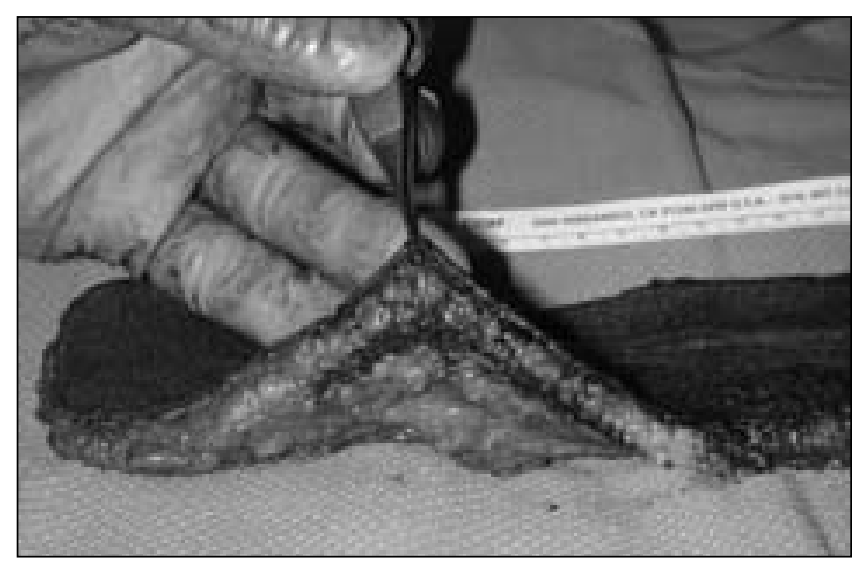

Figure 4) Aspect of the pigmentation seen in all layers of subcutaneous tissue to the level of the muscle fascia

melanocytosis, and depth and distribution of the pigmentation. However, the risk of malignancy is also increased by the presence of larger nevi (greater than $50 \mathrm{~cm}$ ), axial location such as trunk, head and neck, the presence of multiple satellite lesions, and the existence of nodules, dark patches, junctional activity, deep dermal neurogenic element or a blue nevus component $(2,12-19)$.

Congenital nevi with malignant potential are the GCN and nevus sebaceous. Other congenital nevi such as verrucous epidermal nevi and woolly hair nevi are not prone to malignant degeneration. Confusion over the treatment arises because not all giant congenital nevi are pigmented, and malignant potential varies among types (2). More confusion is generated due to the published wide range of malignant transformation risk from less than $1 \%$ to $31 \%(2,4,13)$. While most cases of melanoma arising within the GCN occur before puberty (14), with a reported incidence of melanoma of $8.52 \%$, the life-risk is in the range of $2.3 \%$ $(6,15-18)$.

Given that the risk of malignant disease is lower than previously reported, and that even after surgical treatment the risk does not disappear, especially in those children with a central nervous system component, we believe that it is appropriate to view the removal of the majority of the GCN as a reconstructive aesthetic surgical procedure rather than 
prophylactic cancer surgery (8-12). The advent of tissue expansion has increased the ability to remove a large portion of the GCN while offering a reasonable functional and aesthetic result. It addresses the issue of colour match, which is a problem with skin grafts, as is the scar at the graft donor site. Drawbacks of the use of tissue expanders include infection, hematoma formation, possible flap necrosis and wound dehiscence, expander extrusion and device malfunction. These should be fully discussed with the family.

Giant congenital nevi are very common on the back. They often have a relatively predictable clinical distribution and depth. This consistent pattern was once described as dermatomal (19) or methameric (20). In reviewing the literature, different classification systems have been described, based on the concept of genomic mosaicism, ie, two genotypically distinct cell lineages within one organism (21-24), histological appearance, cutaneous distribution (9) and depth of pigmentation (25). These classification systems try to address the issue of potential malignancy and recurrence following excision. In the present report, the lesion on the back had several concerning features. First, the lesion was located over the spine, which raises the possibility of a central nervous system component and hidden malignancy. Second, the depth of pigmented cells was unusual, because it extended to the level of the muscle fascia. This situation should be considered when planning for more radical treatment. The consequences of leaving a number of cells hidden beneath the skin graft or expanded flap coverage are still unpredictable.

Surgical excision remains the gold standard in the treatment of the GCN. However, promising alternatives are being developed with the expansion of new lasers. Advocates of laser therapy have claimed that removing portions of entire nevus cells could theoretically lessen the risk of malignancy and work as an adjuvant to surgical excision. Conversely, the efficacy of dermabrasion and laser treatment in removing or destroying nevus cells is yet to be established (26-31).

The carbon dioxide laser, the Er:YAG and the Q-switched ruby laser have all been recently used for resurfacing and to selectively treat deep pigmentation (32-34). The Q-switched ruby laser has been shown to have a potent effect on depigmentation, which could be used to lighten deep layers where resurfacing lasers are ineffective. The use of the pigment-specific combined carbon dioxide laser and ruby laser has shown to be effective in lightening small- to medium-sized congenital melanocytic nevi without scarring and textural changes on the skin. One disadvantage of the ruby laser is that permanent depigmentation does not seem to occur (32). The worst concern, however, is that lightening those lesions may camouflage any malignant transformation (2). Other side effects of laser therapies include formation of scar and changes in skin texture and colour (34). There is no evidence at present that the laser used to treat giant congenital nevi could stimulate the melanocytes to malignant changes (7). Nonetheless, longstanding effects on the residual nevomelanocytes are still under investigation (34).

The development of new techniques and the rapid expansion in the growth of lasers may possibly bring new treatment options to the management of congenital melanocytic nevi in the future. Whatever the treatment performed, from deep excision and grafting to laser treatment, there is always the risk of recurrence in the treated areas. In those cases, the nevus cells may reside in the deep subcutaneous fat or underlying muscle.

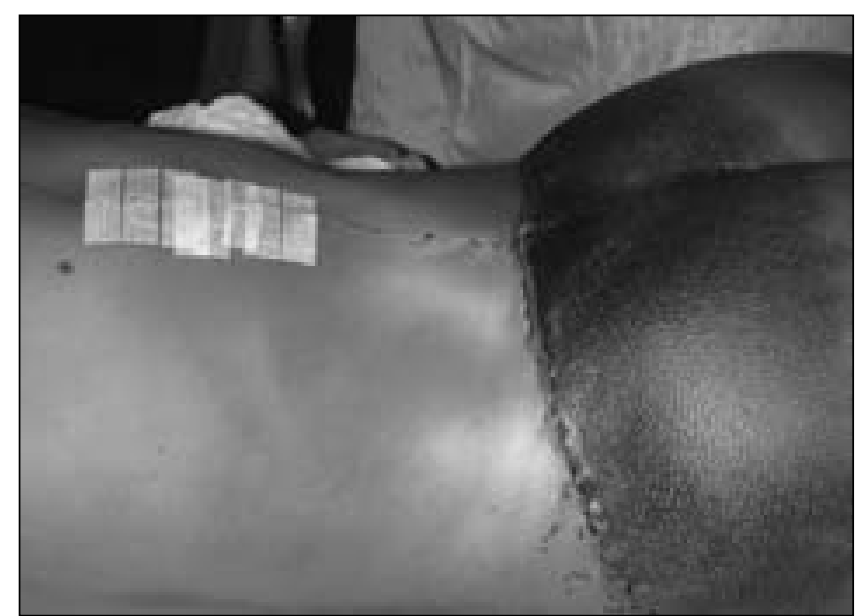

Figure 5) Postoperative result in a patient with a giant congenital nevus

When the decision is made to proceed with some form of treatment, greater attention should be paid to achieving a more functional and aesthetic result, because the excision based only on oncological anticipation is no longer acceptable $(7,18,35)$. The presence of deep pigmentation as exemplified here may reduce the effectiveness of treatment options other than surgical excision.

\section{REFERENCES}

1. Arons MS. Management of giant congenital nevi. Plast Reconstr Surg 2002;110:352-3.

2. Gosain AK, Santoro TD, Larson DL, Gingrass RP. Giant congenital nevi: A 20-year experience and an algorithm for their management. Plast Reconstr Surg 2001;108:622-36.

3. Arons MS, Hurwitz S. Congenital nevocellular nevus: a review of the treatment controversy and a report of 46 cases. Plast Reconstr Surg 1983;72:355-65.

4. Reed WB, Becker SW Sr, Becker SW Jr, Nickel WR. Giant pigmented nevi, melanoma, and leptomeningeal melanocytosis: A clinical and histopathological study. Arch Dermatol 1965;91:100-19.

5. Saraiya H. Giant hairy nevus of the back. Ann Plast Surg 2001;47:583-4.

6. Bittencourt FV, Marghoob AA, Kopf AW, Koenig KL, Bart RS. Large congenital melanocytic nevi and the risk for development of malignant melanoma and neurocutaneous melanocytosis. Pediatrics 2000;106:736-41.

7. Reynolds N, Kenealy J, Mercer N. Carbon dioxide laser dermabrasion for giant congenital melanocytic nevi. Plast Reconstr Surg 2003;111:2209-14.

8. Smith F. Plastic and Reconstructive Surgery: A Manual of Management. Philadelphia: Saunders, 1950.

9. Stenn KS, Arons M, Hurwitz S. Patterns of congenital nevocellular nevi. A histologic study of thirty-eight cases. J Am Acad Dermatol 1983;9:388-93.

10. Zuckerman R, Maier JP, Guiney WB Jr, Huntsman WT, Mooney EK. Pediatric melanoma: Confirming the diagnosis with sentinel node biopsy. Ann Plast Surg 2001;46:394-9.

11. Iconomou T, Michelow BJ, Zuker RM. Tissue expansion in the pediatric patient. Ann Plast Surg 1993;31:134-40.

12. Foster RD, Williams ML, Barkovich AJ, Hoffman WY, Mathes SJ, Frieden IJ. Giant congenital melanocytic nevi: The significance of neurocutaneous melanosis in neurologically asymptomatic children. Plast Reconstr Surg 2001;107:933-41.

13. Mark GJ, Mihm MC, Liteplo MG, Reed RJ, Clark WH. Congenital melanocytic nevi of the small and garment type. Clinical, histologic, and ultrastructural studies. Hum Pathol 1973;4:395-418.

14. Kaplan EN. The risk of malignancy in large congenital nevi. Plast Reconstr Surg 1974;53:421-8. 
15. Quaba AA, Wallace AF. The incidence of malignant melanoma (0 to 15 years of age) arising in "large" congenital nevocellular nevi. Plast Reconstr Surg 1986;78:174-81.

16. DeDavid M, Orlow SJ, Provost N, et al. A study of large congenital melanocytic nevi and associated malignant melanoma: Review of cases in the New York University registry and the world literature. J Am Acad Dermatol 1997;36:409-16.

17. Ruiz-Maldonado R, Tamayo L, Laterza AM, Duran C. Giant melanocytic nevi: Clinical, histopathologic, and therapeutic considerations. J Pediatr 1992;120:906-11.

18. Rhodes AR, Wood WC, Sober AJ, Mihm MC Jr. Nonepidermal origin of malignant melanoma associated with a giant congenital nevocellular nevus. Plast Reconstr Surg 1981;67:782-90.

19. Bauer BS, Vicari FA. An approach to excision of congenital giant pigmented nevi in infancy and early childhood. Plast Reconstr Surg 1988;82:1012-21.

20. Faga A, Rosso R, Buoro M, Valdatta L. Gigantic methameric seborrheic keratosis. Plast Reconstr Surg 2002;109:1198-9.

21. Sugarman JL, McCalmont TH, Frieden IJ, Dover J, Arndt K. Gigantic methameric seborrheic keratosis. Plast Reconstr Surg 2003;111:1775-6.

22. Bolognia JL, Orlow SJ, Glick SA. Lines of Blaschko. J Am Acad Dermatol 1994;31:157-90.

23. Happle R, Rogers M. Epidermal nevi. Adv Dermatol 2002;18:175-201.

24. Jackson R. The lines of Blaschko: A review and reconsideration: Observation of the cause of certain unusual linear conditions of the skin. Br J Dermatol 1976;95:349-60.

25. Casson P, Colen S. Dysplastic and congenital nevi. Clin Plast Surg 1993;20:105-11.

26. Rompel R, Moser M, Petres J. Dermabrasion of the congenital nevocytic nevi: Experience in 215 patients. Dermatology 1997;194:261-7.

27. Grevelink JM, van Leeuwen RL, Anderson RR, Byers HR. Clinical and histological responses of congenital melanocytic nevi after single treatment with Q-switched lasers. Arch Dermatol 1997; 133:349-53.

28. Johnson HA. Permanent removal of pigmentation from giant hairy naevi by dermabrasion in early life. Br J Plast Surg 1977;30:321-3.

29. Weinberg MJ, Al-Qattan MM, Zuker RM, Thomson HG, Lindsay WK. Congenital giant pigmented nevi: Clinical features and risk of malignancy. Can J Plast Surg 1996;4:94-8.

30. Kocialkowski K, Prazynski A, Urbanski G, Gertig G. [Removal of melanocytic nevi as a prophylaxis and early recognition of cutaneous and mucous malignant melanoma.] Ginekol Pol 1993;64:16-8.

31. Hopkins JD, Smith AW, Jackson IT. Adjunctive treatment of congenital pigmented nevi with phenol chemical peel. Plast Reconstr Surg 2000;105:1-11.

32. Park SH, Koo SH, Choi EO. Combined laser therapy for difficult dermal pigmentation: resurfacing and selective photothermolysis. Ann Plast Surg 2001;47:31-6.

33. Reynolds N, Kenealy J, Mercer N. Carbon dioxide laser dermabrasion for giant congenital melanocytic nevi. Plast Reconstr Surg 2003;111:2209-14.

34. Chan HH, Chan E, Kono T, Ying SY, Wai-Sun H. The use of variable pulse width frequency doubled Nd:YAG $532 \mathrm{~nm}$ laser in the treatment of port-wine stain in Chinese patients. Dermatol Surg 2000;26:657-61.

35. Dellon AL, Edelson RL, Chretien PB. Defining the malignant potential of the giant pigmented nevus. Plast Reconstr Surg 1976;57:611-8. 